ISSN: 2162-3104 Print/ ISSN: 2166-3750 Online

Volume 8, Issue 1 (2018), 87-108

(C) Journal of International Students

http://jistudents.org/

doi: 10.5281/zenodo.1101037

\title{
Exploring and Leveraging Chinese International Students' Strengths for Success
}

\author{
Ye He \\ University of North Carolina at Greensboro, United States \\ Bryant Hutson \\ University of North Carolina at Chapel Hill, United States
}

\begin{abstract}
This study used an Appreciative Education framework to explore the strengths of Chinese international students and to identify areas where support is needed during their transition to U.S. higher education settings. Using a convergent mixed methods design with data collected from surveys, interviews and focus groups, the complex nature of the transition process was explored. While commitment and motivation as well as familial support were identified as strengths based on survey data, interview and focus group data revealed additional strengths and how students leverage these strengths to support their transition. The findings led to insights and recommendations for higher education professionals working with Chinese international students specifically, and offered approaches to better understand and support international students in general.
\end{abstract}

Keywords: appreciative education, higher education, international students

According to the Institute of International Education (2016), the overall
number of international students in the United States has reached a record
high of 1,043,839 students in $2015-2016$ academic year. Since $2009-2010$
academic year, China has remained the top country of origin for
international students, providing over one third of international students
(Open Doors, 2016). The increased number of international students have 
brought many benefits to U.S. institutions. However, the rapid increase of international students has also brought challenges to faculty and staff in U.S. colleges, and international students express anxieties and discomfort in their transition process (Belkin \& Jordan, 2016).

Research on international students' transition to U.S. higher education has traditionally focused on either the stress and anxiety from the students' perspectives or on the social, cultural and psychological challenges students face (Wang, Lin, Pang \& Shen, 2007; Wang, et al., 2012; Ying, 2005). Few studies have addressed the transition experience from a strengths-based perspective to explore ways international students leverage their backgrounds to achieve success (Liu \& Brown, 2014; Neri \& Ville, 2008; Yakunina, et al., 2013). Recognizing the linguistic and cultural differences among international students, researchers also caution against overgeneralizing results when studying the international student population in general (Constantine, et al., 2005). Instead, studies focusing on international students from specific linguistic and cultural backgrounds are recommended.

In this study, therefore, we use Appreciative Education (AE) as a strengths-based framework to explore the acculturation process of international students from China. Through surveys, interviews and focus groups, we examined students' strengths and how these strengths were leveraged to support their transition. Recommendations regarding admission and orientation programming are also provided for higher education professionals working with Chinese international students.

\section{LITERATURE REVIEW}

The data collection and analysis process was guided by the acculturation model used widely in the study of international students' transition (Berry, 1997), and the AE framework (Bloom, Hutson, He, \& Konkle, 2013; He, Hutson, \& Bloom, 2014) based on positive psychology principles (Seligman $\&$ Csikszentmihalyi, 2000) and the appreciative inquiry process (Cooperrider \& Srivastva, 1987).

\section{Acculturation Challenges for Chinese International Students}

When different cultural groups encounter each other, acculturation describes the process through which changes to either or both groups may occur (Berry, 1990). International students bring their own cultural backgrounds into the U.S. education culture. As a result, the students and 
the institutions may adapt their cultural norms and practices. To classify the strategies employed in the acculturation process, Berry (1997) detailed them along two dimensions: cultural maintenance, and contact and participation. Cultural maintenance depicts the extent to which international students strive to maintain their home culture while studying in the United States, while contact and participation explains the extent to which students may choose to be integrated into the American culture. Table 1 is an adaptation of Berry's $(1997 ; 2003)$ model applied to acculturation strategies used by Chinese international students in U.S. institutions.

Table 1. Berry's acculturation strategies for Chinese international students.

\begin{tabular}{lcc}
\hline Strategy & $\begin{array}{c}\text { Maintain Chinese } \\
\text { culture }\end{array}$ & $\begin{array}{c}\text { Adopt U.S. } \\
\text { culture }\end{array}$ \\
\hline Participate in interactions with others & Integration & Assimilation \\
Avoid interactions with others & Segregation & Marginalization \\
\hline
\end{tabular}

While it is ideal that international students maintain their own cultural identity and participate in interactions with others when studying in the United States (i.e., integration), multiple researchers have reported that students face stress and challenges in this process (Wang, et al., 2007; Wang, et al., 2012; Ying, 2005). For Chinese students, the main challenges have been described as language barriers, culture shock, and learning shock (Gu, 2011; Huang, 2012; Parris-Kidd \& Barnett, 2011; Zhang, 2016).

Even though most Chinese students start learning English in K-12 schools, most reported that their communicative competency is limited (Wei $\& \mathrm{Su}, 2012$ ). Those with lower levels of language proficiency tend to be more likely to experience acculturative stress (Yeh \& Inose, 2003) and lose confidence in their academic success (Sato \& Hodge, 2009). Further, the sharp differences in cultural values, beliefs, norms and practices between China and the United States can also cause students to experience stress (Leong \& Chou, 1996; Rahman \& Rollock, 2004). Compared to international students from Europe, researchers found that Chinese international students were more likely to experience anxiety, stereotypes and prejudice (Johnston \& Sandhu, 2007; Wan, 2001). In addition to potential language barriers and culture shock, Chinese international students may also experience learning shock during their transition (Griffiths, Winstanley \& Gabriel, 2005). The unfamiliarity of American approaches to teaching can cause Chinese international students to experience frustration and anxiety, especially in terms of participating in class discussions, raising 
questions in class, and engaging in critical reflections and argumentations (Durkin, 2011; Huang, 2012). Although studies on Chinese international students' acculturation also indicated that social support is negatively associated with acculturation stress (Tsai \& Wong, 2012; Ye, 2006), few studies have explored other associated factors and student attributes that support their initial transition.

\section{Appreciative Education Framework}

Bertram et al. (2014) noted that the majority of existing research regarding international students used quantitative methods, and few involved Asian student populations (Zane \& Mak, 2003). Among the few qualitative studies included in the Bertram et al. (2014) review, none focused on strengths Chinese students bring into their studies in the United States. To deepen our understanding of unique strengths among Chinese international students, the AE framework guided the convergent mixed methods design in this study.

AE was developed based on positive psychology theories and appreciative inquiry principles to challenge problem-focused thinking (Bloom, et al., 2008; 2013; Cooperrider \& Srivastva, 1987; Seligman, 2002; 2011; Tschannen-Moran \& Tschannen-Moran, 2011). The AE framework was designed "for educators to embrace positive mindsets, leverage learners' assets and strengths, and empower learners to take ownership of the learning process for their academic success" (He, et al., 2014, p.1). The framework entails three key principles: (a) learning involves metacognitive and affective development as well as cognitive growth; (b) individuals' past experience and vision for the future impacts their present actions and learning behaviors; and (c) social interactions assist in the positive reconstruction of individual experiences and the pursuit of alternative pathways to success. The AE framework extends the 4-D model of appreciative inquiry (Cooperrider \& Srivastva, 1987) and entails six interconnected phases: Disarm, Discover, Dream, Design, Deliver, and Don't Settle. The Disarm phase invites participants to reflect on their assumptions and strive to build trusting and safe environments for interaction. Positive and open-ended questions are used in the Discover phase to explore participants' strengths through past successes. Future aspirations are shared during the Dream phase to establish common visions and personal goals. During the Design phase, an action plan is constructed to reflect both one's strengths and aspirations. The action plan is carried out during the Deliver phase through leveraging one's internal and external 
strengths. Finally, in the Don't Settle phase, participants are challenged to uncover new strengths and aspirations and continue to design action plans for future success. While the AE framework has been widely used in higher education settings to guide both the academic advising process (Bloom, et al., 2008; 2013) and classroom instruction (Bloom, Hutson, He, \& Robinson, 2011; He, 2013), no empirical studies used this framework to guide the design of studies involving international students.

Building upon both the AE framework and previous studies on international students' acculturation, in this study we focused data collection and analysis on Chinese students' strengths. The process of this research also revealed ways to understand and support targeted groups of international students from a strengths-based perspective, as well as identify recommendations for higher education professionals working with Chinese international students.

\section{RESEARCH METHOD}

A convergent mixed methods design was employed in this study (Creswell \& Plano Clark, 2011). Two specific research questions guided the data collection and analysis: (a) What are Chinese international students' perceptions of their transition experiences? (b) What are the strengths they use to support their transition?

\section{Participants}

Sixty-one first-year Chinese students enrolled in a mid-sized public university in the Southeast United States volunteered to participate in this study and provided consent. These students came from various provinces in China and all had successfully completed at least a high school education before entering the university. Most of the participants came to complete their undergraduate studies $(N=53,87 \%)$ and eight students $(13 \%)$ came for graduate studies. Regardless of their educational backgrounds, all participants were required to take intensive English language courses before enrolling in major-specific courses.

Participants' ages ranged from 17 to 22, except for one participant who was 29 at the time of the study. Twenty-nine participants were female $(48 \%)$. A majority of these participants intended to major in business $(N=$ $37,61 \%)$, with the rest planning to major in science $(N=9,15 \%)$, humanities $(N=8,13 \%)$, fine arts $(N=6,10 \%)$, and one undecided. The large percentage of participants interested in business reflects the general 
trend among Chinese international students in the United States as well as the positive academic reputation of the university's business program. Eleven (18\%) participants reported having visited the United States previously. Seven out of the eleven participants previously participated in study abroad programs to the United States for one semester to 1 year, and the other four traveled to the United States for vacations lasting from 7 to 20 days.

\section{Data Collection and Analysis}

Both quantitative and qualitative data were collected to triangulate and corroborate the findings (Creswell \& Plano Clark, 2011). Quantitative data were collected using an adapted Appreciative Advising Inventory (He, Hutson, \& Bloom, 2010) during students' first year at the institution. The instrument included eight subscales, focusing on both internal strengths (Language, Culture, Motivation and Commitment, Values and Identity), and external strengths (Academic Preparedness, Communication and Collaboration, Familial Support, and Network and Community). Each subscale contained five Likert-scale items. All items on this instrument were presented to the students in both English and Chinese. Participants were asked to rate the statements on a 3-point Likert scale: not like me, somewhat like me, and just like me. The overall reliability of the instrument as measured using Cronbach's alpha was .92.

Additionally, individual interviews were conducted using a protocol designed to follow the AE framework (Bloom, Hutson, \& He, 2008). Focus group discussions were conducted at the end of each semester for two semesters to engage all participants in discussions of their strengths and transition experiences. Participants were invited to share their thoughts in either English or Chinese during the interviews and focus group discussions. The interviews and focus group discussions were conducted by ChineseEnglish bilingual faculty and staff who work closely with the participants. In most cases, participants chose to share in Chinese.

Data were analyzed in two phases. During the first phase, quantitative and qualitative data were analyzed separately. Descriptive statistics were used to report quantitative findings. Patterns and themes were highlighted based on the qualitative data (Patton, 1990). During the second phase, quantitative and qualitative findings were combined to address the research questions (Creswell \& Plano Clark, 2011). 


\section{RESULTS}

\section{Students' Transitional Experiences}

Through their interviews and focus group discussions, participants shared their experiences during their first year in a U.S. university. All participants commented on the challenges they experienced in living more independently, their discomfort in terms of food, relative lack of public transportation, and challenges with English language learning.

\section{Independence and Time Management}

Because most of the participants came to the United States right after high school, this was the first time they have lived away from their family. When asked about their impression of their first year, several of them commented, "I feel free!" One student, for example, said in the interview, "Here no one tells me what I need to do. I feel so free. So long as I do not break the law, I can do whatever I want." They also felt that they were expected to live more independently and manage their own daily life. One student revealed his realization in the interview,

"It did not really hit me until the third day I was here. The first day, I got in the dorm. I had my stuff in the suitcase out there in the room. I was tired so I just went to sleep. The next day, I got up and saw the stuff was still out there. I didn't think much about it. But then, the third day, I woke up and saw the suitcase was still there. I realized I had to do something about it. I am not at home any more. I have to do things myself now."

Almost half of the participants commented on the importance of time management. One student recalled her high school experience, "In China, we had classes all day and we had a lot of homework. We were always told what to do." After spending some time in the United States, she started to realize the importance of managing her own time. She learned to set her own schedule and tried to arrange her assignments and tasks throughout the week. A few students pointed out the cultural difference in the perception of time. One of them mentioned that "I think it [the concept of time] is just different. In the United States, people are stricter about time. They want you to show up at the exact time and everyone works with a calendar. That's not the case in China." 


\section{Discomfort and Challenges}

While some participants reported that they did not experience any discomfort during their transition into life in the United States, most of them commented on difficulties with food and transportation. Even though the university is located in a mid-sized town in the United States, public transportation and access to authentic Chinese food are very limited. Most students reported that they did not think about these as challenges before they came to the United States. Several students said, "I don't like the food here. It's just hamburger and pizza. I cannot get used to that." Many of them started cooking their own meals during the weekends and the most common dish they make is the Chinese-style "hotpot" (huo guo, 火锅).

English language proficiency was noted as a major barrier by all students. Participants discussed two major challenges with language learning: participating in daily conversations and meeting the academic writing expectations.

Regardless of their language proficiency levels, almost all students commented on the challenges they experienced in daily conversations. As one participant commented, "Sometimes, you just don't know the word to describe a common item you use. We have never learned those in our English classes in China." Another participant gave an example of her shopping experience,

"I was trying to get a pink lipstick in the store. The assistant picked out one for me and I tried it. I felt that it was too "white", but she said that was "pink." I spent a lot of time describing to her what I meant. I think what I really meant was that the lipstick was too pale looking on me, but I didn't know how to say it."

Listening comprehension is one of the most challenging areas for many participants, especially when communicating with English speakers with different accents. One participant shared his experience changing information on a flight ticket he purchased,

"I got on the phone with someone who speak English with a Hispanic accent. We spent about 2 hours on the phone to change that information. I couldn't understand what he was saying and he had trouble understanding me."

Most participants felt that if they had a larger vocabulary and spent more time in the United States, they would not experience as many challenges in listening comprehension. 
Academic writing is another area all participants commented on. Interestingly, most participants said that "I just need to think differently." They reported that the expectations for English writing assignments were very different in China compared to the United States. Several of them recalled, "in China, you just need to make sure you cover the key points and the writing meets the word requirements." However, they felt that they could not follow the U.S. expectations for the structure of academic writing, especially in their language courses. One student commented in the interview,

"The teacher asked us to give examples to support our ideas. But a lot of times, the teachers just don't understand what we write. For example, when we write about comparison and contrasts. Usually, in China, we just write the points together to compare. In the United States, the teacher won't understand it unless I separate all of them. The teacher just doesn't understand my writing."

Even for some graduate students who majored in English language as undergraduates, learning the structure of academic writing remains a challenge.

\section{Chinese International Students' Strengths}

Participants' survey responses, interviews and focus group discussions allowed us to explore perceived strengths using both quantitative and qualitative data.

\section{Quantitative Results}

As indicated in Figure 1, participants reported the highest average rating for subscales regarding Culture (subscale $M=13.25$ ), Familial Support (subscale $M=13.18$ ), and Motivation and Commitment (subscale $M=12.97)$. The highest scored individual items were "My family supports me." (item mean=2.84), "I use my knowledge of cultures in my learning and working environment." (item $M=2.82$ ) and "I am committed to completing my academic program at this institution." (item $M=2.77$ ).

In addition to the three subscales, it is noteworthy that Item 2 regarding language ("I switch among two or more languages/dialects in different contexts."), Item 20 regarding values and identity ("I am optimistic about my future."), and Item 36 regarding network and community ("I am 
associated with strong networks and communities") were also rated highly by participants.

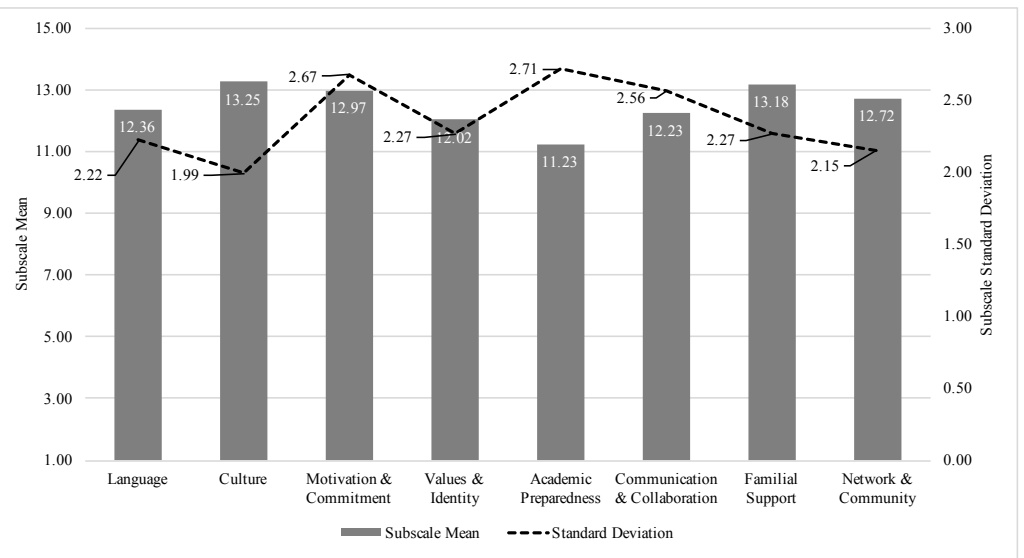

Figure 1. Chinese international students' strengths and assets.

The mean and standard deviation of participants' survey responses were also plotted to identify items with relatively high mean scores and low standard deviations These items indicate the group assets reported by the participants (see Table 2). It was clear that the three items with the highest ratings also has the lowest variability among the group. Conversely, items regarding academic preparedness (Items 21-25) seemed to demonstrate the highest variability as a subscale. It was also interesting to note that while familial support was clearly identified by the group as a strength overall, Item 33, "I enjoy sharing my experiences with my family," was scored relatively low and with high variability among the group. Similarly, Item 37, "I am actively engaged in my networks and communities," was scored relatively low with high variability, even though the subscale network and community was rated relatively high by participants. Finally, two items regarding the language subscale: Items 3 ("I enjoy doing things using a language other than English.") and 4 ("My understanding of a non-English language or dialect helps me to learn English.") were scored relatively low with high variability.

\section{Qualitative Results}

In qualitative interviews and focus group discussions, participants were asked directly to reflect on their strengths. This was not an easy question for most participants to address. We analyzed participants' 
responses to all questions to explore strengths reflected in their discussions. While we did identify themes that support the quantitative results, we also noted some discrepancies.

Table 2. Chinese international students' top 10 strengths.

\begin{tabular}{|c|c|c|c|}
\hline Subscale & Item & $M$ & $S D$ \\
\hline Language & $\begin{array}{l}\text { 2. I switch among two or more languages and dialects } \\
\text { in different contexts. }\end{array}$ & 2.70 & 0.52 \\
\hline \multirow[t]{3}{*}{ Culture } & $\begin{array}{l}\text { 7. I adapt my behaviors to act appropriately in } \\
\text { different cultural settings }\end{array}$ & 2.67 & 0.53 \\
\hline & $\begin{array}{l}\text { 9. My understanding of different cultures helps me to } \\
\text { work with others. }\end{array}$ & 2.74 & 0.51 \\
\hline & $\begin{array}{l}\text { 10. I use my knowledge of cultures in my learning } \\
\text { and working environments. }\end{array}$ & 2.82 & 0.42 \\
\hline \multirow{2}{*}{$\begin{array}{l}\text { Commitment } \\
\text { and } \\
\text { motivation }\end{array}$} & $\begin{array}{l}\text { 13. I am confident that I can overcome any obstacles } \\
\text { to complete my academic program. }\end{array}$ & 2.70 & 0.53 \\
\hline & $\begin{array}{l}\text { 14. I am committed to completing my academic } \\
\text { program at this institution. }\end{array}$ & 2.77 & 0.46 \\
\hline $\begin{array}{l}\text { Values and } \\
\text { identity }\end{array}$ & 20. I am optimistic about my future. & 2.70 & 0.52 \\
\hline \multirow{2}{*}{$\begin{array}{l}\text { Familial } \\
\text { support }\end{array}$} & 31. My family supports me. & 2.84 & 0.41 \\
\hline & $\begin{array}{l}\text { 35. Familial support strengthens my identity, } \\
\text { motivation and commitment. }\end{array}$ & 2.72 & 0.52 \\
\hline $\begin{array}{l}\text { Network and } \\
\text { community }\end{array}$ & $\begin{array}{l}\text { 36. I am associated with strong networks and } \\
\text { communities. }\end{array}$ & 2.70 & 0.49 \\
\hline
\end{tabular}

Consistent with the quantitative findings, participants showed strong commitment and motivation to complete their studies at the institution. All participants shared their short-term and long-term academic goals and explicitly commented on their desire to take teachers' feedback and do well in their coursework. For most students, their commitment and motivation were highly related to their family support. One student commented, "Since my family sends me all the way to the United States, I feel like I need to take this opportunity and learn as much as I can. I want to be able to do something different when I get home." Others also described their desire to become more marketable once they finish their studies and return to China. Over half of the participants mentioned being able to speak the English 
language and becoming familiar with the American culture as strengths they will have over Chinese peers once they return to China.

Network and community was another strength highlighted by the participants. Although the institution does not have a large number of Chinese students on campus compared to larger institutions in the same state or elsewhere in the United States, participants reported that they made friends as soon as they arrived. When asked about their favorite experiences in the United States, most of them said "I enjoyed getting to know people." Because students live in residence halls with two or three roommates, even students who considered themselves not as outgoing at least got to know their roommates well. One participant said in the interview, "I was surprised that I did not feel lonely here like I expected. I really like talking with my friends."

Communication and collaboration did not emerge as one of the salient strengths for the group based on the quantitative results. However, in interviews and focus groups, this was noted as a clear strength among almost all participants. Recognizing that English language proficiency was a challenge, participants commented on how much they enjoyed group work in classes and collaborating with peers from different cultural backgrounds. Most participants reported that the requirement of group discussions and group work for class projects were very different from classes they were accustomed to attending in China. In their residence halls and language classes, many of them also have had the opportunity to work with international students from other countries and to learn from one another. One participant even mentioned that he can recognize some phrases in Arabic, Japanese, and Korean through getting to know his peers from other countries.

Another strength that was not noted in the quantitative data but was observed through the qualitative analysis was students' academic preparedness. While most students expressed concerns as to their lack of knowledge about English vocabulary words in their major and the challenge of following class discussions with other American students, they commented on learning strategies they feel comfortable employing. Observing how her Chinese peers study, one participant commented, "A lot of Chinese students learn things so quickly. Because of the way we were taught in China, I think we are good at memorizing things and making connections." In addition, background knowledge on major-related content or academic topics was viewed as a strength. Participants who intend to major in Business, for example, perceived math knowledge as one of their strengths. One participant said, 
"I live with an American roommate now. He's taking a college math class. I am still taking my language classes. So he helps me with my writing and I can help him with his math. College math in the United States is really not hard. It's like high school math at home. I am good at it."

Content-specific knowledge and skills were reported by art majors. For example, one music major who came for graduate study expressed her desire to join the performance-based classes soon,

"I have met my advisor. We played some pieces together. I really enjoyed it. I am confident on my skills, but of course, my language is not good enough. But you know, in some classes, they can just show me how to do it, and I am sure I will understand. I also know all the music-related words. I just don't communicate very well."

Clearly, the student did not necessarily label her performance skill as an academic strength in the discussion, but it was made evident that she could benefit from leveraging her strength to participate in major-specific classes before meeting the language proficiency requirements. As she said, "I think learning English will be a lot more meaningful for me if I can talk about music."

Interestingly, aspects of culture (i.e., cultural knowledge and intercultural skills) and familial support did not emerge as strengths based on interview and focus group discussions. When prompted, participants did recognize that it can be an advantage to be familiar with both Chinese and American cultures when they return to China, and that their family fully supports their study in the United States. However, only one or two participants would consider their understanding of cultures and the support they receive from their families to be among their strengths.

\section{Strengths Used to Support Students' Transition}

Considering the findings from the research, it appears that Commitment and Motivation as well as Network and Community are two areas of strength participants not only reported possessing, but that they leveraged to support their transition in the United States. They were able to form bonds within the community of Chinese students, connect with other international students, and start to engage in the local community within and beyond the college campus.

The Chinese student community was mentioned the most by all participants. Because food and transportation were two major discomforts 
for almost all participants, they reported forming bonding relationships through shopping and cooking experiences. Over half of the students said that they have learned how to cook since they arrived in the United States. As one student mentioned, "At home, I just saw my mom cooking. I never had the chance to do that. When we went out with friends, we just ate at the restaurant. But now, I can at least cook for myself." They usually form small groups to cook together during the weekend. Some of them have also attempted baking and described having made cakes themselves. Shopping appeared to be another bonding experience for students, because they needed to find transportation through asking friends for rides or using public transportation, taxis or Uber. A few mentioned shopping experiences in which they booked tickets and took the train to a nearby large city. Some leaders emerged through these experiences who continued to organize cooking or shopping experiences for small groups.

Living in residence halls with students from both the United States and other countries and participating in some common activities on campus also allowed participants to know more peers and learn more about other cultures. Although language presented an obstacle, since they shared similar goals of enhancing their English proficiency and becoming integrated into campus life, participants did not find it challenging to collaborate with other international students. In fact, making friends with those from other cultures was one of the experiences they enjoyed most. Most of them commented on how the experience broadened their understanding of the world and allowed them to see things from different perspectives.

Depending on the local connections participants made, they engaged in local communities in different ways. Some participants, for example, were more engaged through local churches. In the town where the campus is located, there are many churches that have outreach programs designed specifically for international students. Some groups of students were invited to church activities and regularly attended Bible studies and worship services. While some might be attending the activities for religious purposes, most seemed to perceive these activities as opportunities to learn more about local culture. As one student commented, "I just think people are so nice [at church]. They are willing to help us, and I am learning a lot about American culture too." Students who have decided upon an academic major also commented on local activities that were relevant to their course of study. For example, one music major mentioned a local concert she attended the first week she arrived in the United States. Several education majors were offered opportunities to do volunteer work at the communitybased Chinese language school as well as at a Saturday program at a local 
middle school. Those who have not had the opportunity to engage in these types of experiences also expressed interest in participating in more majorrelated internship or community-based activities while in the United States. Finally, some students were actively engaged in local festivals and activities organized by the university or by the city. One student commented extensively on the local folk festival he was able to attend. He came to the United States with relatively low English oral proficiency skills, but he found it helpful to participate in these activities and get to know people:

"I carry a bag with the university logo on it. So when I am at those events, people usually ask me about my school and my experiences. We have a lot to talk about. In China, most young people play video games so we talk about that. But here, they have different hobbies. I noticed that a lot of Americans play some instruments and maybe do some crafts. I am learning guitar from one of my American friends now. I am excited about it."

The extent to which participants engaged in activities seemed to be more related to their personality and attitude rather than their English proficiency levels. Some students who referred to themselves as being more reserved tended to only participate in activities organized by the university.

\section{DISCUSSION AND IMPLICATIONS}

Applying the AE framework with Chinese international students, we were able to uncover strengths students can leverage to not only ease their transition to the U.S. higher education system, but also maximize their learning while pursuing their degrees. The process also revealed the need for higher education professionals and students to shift their mindsets from filling the language and cultural gaps to uncovering and leveraging their strengths. Further, it is important to recognize that strengths and challenges may co-exist. In this section, we also caution higher education professionals and students to engage in critical reflections on students' strengths.

\section{Strengths-Based Perspectives on International Students' Transition}

Findings from interviews and focus group discussions clearly illustrated the lack of practice in reflecting on ones' strengths among our participants. In most discussions, when participants were asked to discuss their strengths, there was usually a long pause. Several participants asked for clarification, "What do you mean my strengths?", "You mean, how I am 
better than the Americans?". Many also responded to the question by saying, "I cannot think of any strengths I have." This was perhaps not surprising given the Chinese values related to modesty and the tradition to "learn from others' strengths to overcome my shortcomings" (qu chang bu duan, 取长补 短). Given the prevalence of deficit-based perspectives in education in general (He, 2013; He, Hutson, \& Bloom, 2014), we would argue that the "filling-the-gaps" mentality is not culturally specific either. Through this study, however, we identified several areas of Chinese international students' strengths that can be leveraged for their successful transition in U.S. higher education.

First, the areas of communication and collaboration as well as network and community appeared to be strengths for individual participants and the Chinese international students as a group. Coming from a collectivist cultural tradition, it is important for most Chinese students to feel that they belong to various groups. In this study, it was evident that students were able to turn the discomfort they experienced into bonding opportunities to form peer groups and friendships. Further, engagement opportunities through local events and major-specific volunteering or field experiences also expanded international students' community building and support networks. Intentionally connecting international students with such local opportunities would not only benefit the students, but also bring new assets to the local community. Educators may also consider guiding international students to participate in relevant experiential learning activities.

Second, academic preparedness was an area that can be neglected as a strength by both international students themselves and higher education professionals. International students coming from non-English speaking countries were typically perceived as in need of academic English language support. While this support is definitely critical, this research project suggests that developing English proficiency through content area instruction would make language learning a lot more meaningful and engaging for students. While in $\mathrm{K}-12$ settings, the sheltered instruction model has been widely used for many years (Echevarria, Vogt, \& Short, 2007), in higher education settings intensive English instruction is still delivered in an isolated, added-on fashion. To meet the needs of the growing international student population, we challenge higher education institutions to seek innovative approaches to embed English language development into degree coursework rather than relying on short-term, intensive language programs. 
Third, the group of Chinese international students we worked with did not identify their understanding of multiple languages and cultures as among their strengths. While this may not be surprising, we wonder how higher education professionals can intentionally engage international students in discussing the linguistic and cultural assets they bring into U.S. classrooms.

\section{Interpretation of Students' Strengths}

While we uncovered Chinese international students' strengths in this study, we would also caution the interpretation of the self-reported strengths students revealed and challenge students to engage in further critical reflections of their strengths.

One of the key strengths revealed by participants was their commitment and motivation. All participants were determined to complete their course of study and wanted to do well in coursework. Some participants commented that the difference between Chinese students and other students was that Chinese students took teachers' feedback more seriously and followed the teachers' instruction well. When asked about additional support they need, some of them even commented that they wished they had more homework so they knew what they needed to focus on for practice. As many students noted, becoming independent was one of the major learning experiences they had coming to the United States. Although it is important for these students to follow teachers' guidance and stay committed to academic activities, we would also challenge them to critically reflect on their own learning processes and become more independent in their academic studies. Learning how to set their own pace, use their own strategies, and explore their own interests would be strategies students need to further develop.

Related to their commitment and motivation to succeed in their academic studies was participants' high level of familial support. Participants described frequent contact with their parents and their parents' support for academic studies. When asked about why they chose to come to study in the United States, the majority of the participants said it was their parents' desire. Moreover, when asked about their major choices, the majority also portrayed their parents as the decision makers. Some of them even commented on how, even though their major choices do not align with their interests, they would complete their program of study just because their parents thought the major would be the best for their future. This sense of familial obligation is rooted in Chinese culture. While it can strengthen 
students' commitment to their major as well as their motivation for learning, students may overlook opportunities to seek alternative pathways to realize their own dreams. While parents may be trying their best to plan for their children's future, lacking experiences in U.S. higher education settings and not knowing the specific requirements and job prospects of various majors, parents may not be the best decision maker for students. We would caution against extremes in which students follow their parents' direction blindly or completely abandon familial support and treat family suggestions as irrelevant. Higher education professionals' guidance on how to critically examine feedback from families and utilize familial support as a strength for success is critical.

\section{CONCLUSION}

In this study, we explored the transition experiences of Chinese international students in a U.S. higher education institution using the AE framework. In addition to offering insights for higher education professionals to more effectively leverage the strengths of international Chinese students, this study also provided an approach for educators to uncover and celebrate international students' strengths. To further the study of AE with international student populations, we would like to encourage international students to consider using the survey instrument and interview protocol as reflective tools during their transition in U.S. universities and colleges. In addition, we would like to work with higher education professionals to explore the use of $\mathrm{AE}$ as a pedagogical tool to revisit existing orientation, first-year, and intensive English programs designed for international students. As Berry (1997) noted, the acculturation process should not be one-way. It is the changes across both groups and the promotion of cultural plurality that would create an environment that cultivates integration (see Table 1). We believe that through the intentional discovery of students' strengths, higher education professionals will be able to design innovative programs that not only support international student transitions, but also capitalize on their strengths to enrich the learning experiences for all students.

\section{REFERENCES}

Belkin, D. \& Jordan, M. (2016). Heavy recruitment of Chinese students sows discord on U.S. campuses. Retrieved from: http://www.wsj.com/ articles/heavy-recruitment-of-chinese-students-sows-discord-on-u-scampuses- 1458224413 
Berry, J. W. (1990). Psychology of acculturation. In J. Berman (Ed.). Cross-cultural perspectives: Nebraska Symposium on Motivation (pp. 201-234). Lincoln, NE: University of Nebraska Press.

Berry, J. W. (1997). Immigration, acculturation, and adaptation. Applied Psychology: An International Review, 46(1), 5-68.

Berry, J. W. (2003). Conceptual approaches to acculturation. In K. M. Chun, P. B. Organista, \& G. Marin (Eds.), Acculturation: Advances in theory, measurement, and applied research (pp. 17-37). Washington, DC: American Psychological Association.

Bertram, D. M., Poulakis, M., Elsasser, B. S., \& Kumar, E. (2014). Social support and acculturation in Chinese international students. Journal of Multicultural Counseling and Development, 42(2), 107-124.

Bloom, J. L., Hutson, B. L., \& He, Y. (2008). The appreciative advising revolution. Champaign, IL: Stipes Publishing.

Bloom, J. L., Hutson, B. L., He, Y. \& Robinson, C. (2011). Appreciative college instruction: Becoming a force for positive change in student success courses. Urbana-Champaign, IL: Stipes Publishing.

Bloom, J. L., Hutson, B. L., He, Y., \& Konkle, E. (2013). Appreciative education. In P. C. Mather \& E. Hulme (Eds.) Positive psychology and appreciative inquiry in higher education: New directions for student services, (Vol. 143, pp. 5-18). Hoboken NJ: Wiley.

Constantine, M., Kindaichi, M., Okazaki, S., Gainor, K., \& Baden, A. (2005). A qualitative investigation of the cultural adjustment experiences of Asian international college women. Cultural Diversity and Ethnic Minority Psychology, 11, 162-175.

Cooperrider, D. L. \& Srivastva, S. (1987). Appreciative inquiry in organizational life. In R. W. Woodman \& W. A. Pasmore (Eds.), Research in organizational change and development (pp. 129-170), Greenwich, CT: JAI Press.

Creswell, J. W., \& Plano Clark, V. L. (2011). Designing and conducting mixed methods research. (2nd ed.). Thousand Oaks, CA: Sage.

Durkin, K. (2011). Adapting to western norms of critical argumentation and debate. In L. Jin \& M. Cortazzi (Eds.), Researching Chinese learners (pp. 274291). New York, NY: Palgrave Macmillan.

Echevarria, J., Vogt, M. E., \& Short, D. (2007). Making content comprehensible for English learners: The SIOP model (3rd ed.). Boston, MA: Allyn \& Bacon.

Griffiths, D. S., Winstanley, D., \& Gabriel, Y (2005). Learning shock: The trauma of return to formal learning. Management Learning, 36, 275-297.

$\mathrm{Gu}$, Q. (2011). An emotional journal of change: The case of Chinese students in UK higher education. In L. Jin \& M. Cortazzi (Eds.), Researching Chinese learners (pp. 212-232). New York, NY: Palgrave Macmillan.

He, Y., Hutson, B. L., \& Bloom, J. L. (2010). Appreciative team building in learning organizations. In P. Hagen \& T. Kuhn (Eds.), Scholarly inquiry in academic advising: NACADA Monograph Series M20. (pp. 133-141). 
Manhattan, KS: National Academic Advising Association.

He, Y. (2013). Developing teachers' cultural competence: Application of appreciative inquiry in ESL teacher education. Teacher Development, $17(1), 55-71$.

He, Y., Hutson, B. L., \& Bloom, J. L. (2014). A call for action to engage in appreciative education. Journal of Appreciative Education, 2(1), 1-9.

Huang, Y. (2012). Transitioning challenges faced by Chinese graduate students. Adult Learning, 23(3), 138-147.

Institute of International Education. (2016). Open Doors report. Retrieved from: http://www.iie.org/Research-and-Publications/Open-Doors

Johnson, L. R., \& Sandhu, D. S. (2007). Isolation, adjustment, and acculturation issues of international students: Intervention strategies for counselors. In H. Singaravelu \& M. Pope (Eds.), A handbook for counseling international students in the United States (pp. 13-35). Alexandria, VA: American Counseling Association.

Leong, F. T. L., \& Chou, E. L. (1996). Counseling international students. In P. B. Pedersen, J. G. Draguns, W. J. Lonner, \& J. E. Trimble (Eds.), Counseling across cultures (4th ed., pp. 210-242). Thousand Oaks, CA: Sage.

Liu, D. \& Brown, B. B. (2014). Self-disclosure on social networking sites, positive feedback, and social capital among Chinese college students. Computers in Human Behavior, 38, 213-219.

Neri, F. V. \& Ville, S. (2008). Social capital renewal and the academic performance of international students in Australia. Journal of Socio-Economics, 37(4), $1515-1538$.

Parris-Kidd, H., \& Barnett, J. (2011). Cultures of learning and student participation: Chinese learners in a multicultural English class in Australia. In L. Jin \& M. Cortazzi (Eds.), Researching Chinese learners (pp. 169-187). New York, NY: Palgrave Macmillan.

Patton, M.Q. (1990). Qualitative evaluation and research methods (2nd ed.). Thousand Oaks, CA: Sage.

Rahman, O., \& Rollock, D. (2004). Acculturation, competence, and mental health among South Asian students in the United States. Journal of Multicultural Counseling and Development, 32, 130-141.

Sato, T., \& Hodge, S. R. (2009). Asian international doctoral students' experiences at two American universities: Assimilation, accommodation, and resistance. Journal of Diversity in Higher Education, 2(3), 136-148.

Seligman, M. E. P. (2011). Flourish: A visionary new understanding of happiness and well-being. New York, NY: Free Press.

Seligman, M. E. P., \& Csikszentmihalyi, M. (2000). Positive psychology: An introduction. American Psychologist, 55, 5-14.

Seligman, M. (2002). Authentic happiness: Using the new positive psychology to realize your potential for lasting fulfillment. New York: Free Press. 
Tsai, P. \& Wong, Y. J. (2012). Chinese and Taiwanese international college students' participation in social organizations: Implications for college counseling professionals. Journal of College Counseling, 15(2), 144-156.

Tschannen-Moran, M., \& Tschannen-Moran, B. (2011). Taking a strengths-based focus improves school climate. Journal of School Leadership, 21(3), 422448.

Wan, G. (2001). The learning experience of Chinese students in American universities: A cross-cultural perspective. College Student Journal, 35(1), 28-44.

Wang, K. T., Heppner, P. P., Fu, C. Zhao, R., Li, F., \& Chuang, C. (2012). Profiles of acculturative adjustment patterns among Chinese international students. Journal of Counseling Psychology, 50(3), 424-436.

Wang, Y. W., Lin, J. C. G., Pang, L. S., \& Shen, F. C. (2007). International students from Asia. In F. T. L. Leong, A. Ebreo, L. Kinoshita, A. G. Inman, L. H. Yang, \& M. Fu (Eds.), Handbook of Asian American psychology (2nd ed., pp. 245-261). Thousand Oaks, CA: Sage.

Wei, R. \& Su, J. (2012). The statistics of English in China. English Today, 28, 10 14.

Yakunina, E. S., Weigold, I. K., Weigold, A., Hercegovac, S., \& Elsayed, N. (2013). International students' personal and multicultural strengths. Journal of Counseling and Development, 91(2), 216-223.

Ye, J. (2006). An examination of acculturative stress, interpersonal social support, and use of online ethnic social groups among Chinese international students. Howard Journal of Communications, 17, 1-20.

Yeh, C. J., \& Inose, M. (2003). International students' reported English fluency, social support satisfaction, and social connectedness as predictors of acculturative stress. Counselling Psychology Quarterly, 16, 15-28.

Ying, Y. (2005). Variation in acculturative stressors over time: A study of Taiwanese students in the United States. International Journal of Intercultural Relations, 29, 59-71.

Zane, N., \& Mak, W. (2003). Major approaches to the measurement of acculturation among ethnic minority populations: A content analysis and an alternative empirical strategy. In K. M. Chun, P. B. Organista, \& G. Marin (Eds.), Acculturation: Advances in theory, measurement, and applied research (pp. 39-60). Washington DC: American Psychological Association.

Zhang, Y. (2016). International students in transition: Voices of Chinese doctoral students in a U.S. research university. Journal of International Students, 6(1), 175-194.

YE HE, $\mathrm{PhD}$, is an associate professor in the School of Education at the University of North Carolina at Greensboro. Her research focuses on the promotion of strengths-based, community-engaged culturally responsive practices in education. Email: y_he@uncg.edu 
BRYANT HUTSON, PhD, is Director of Assessment in the Office of Institutional Research and Assessment at the University of North Carolina at Chapel Hill. His research focuses on academic advising, student success and retention programming, and the use of assessments to enhance the quality of student success efforts. Email: Bryant.Hutson@gmail.com

\section{ACKNOWLEDGMENTS}

We would like to acknowledge the assistance from Michael Chen, Enoch Chow, Juan Sun, and Xizi Blackwell from New Mind Education. 